\title{
Quality of Urban Environment: A Critical Review of Approaches and Methodologies
}

\author{
Mohammad Firoz Khan', Subia Aftab², Fakhruddin² \\ ${ }^{1}$ Department of Geography, Jamia Millia Islamia (University), New Delhi, India \\ ${ }^{2}$ Department of Geography, Aligarh Muslim University, Aligarh, India \\ Email: mohdfirozkh@gmail.com
}

Received 23 October 2015; accepted 8 December 2015; published 11 December 2015

Copyright (C) 2015 by authors and Scientific Research Publishing Inc.

This work is licensed under the Creative Commons Attribution International License (CC BY). http://creativecommons.org/licenses/by/4.0/

c) (i) Open Access

\begin{abstract}
It is a well-known fact that quality of environment in urban habitats has deteriorated throughout the world over time and the down-slide still continues. It is a matter of great concern as it affects human well-being and health. This problem under the general umbrella of quality of life studies has been examined from different angles. At the centre stage in this paper it is the quality of environment from a human perspective to inform the policy makers about the hiatus between objective (empirical) and perceived quality of environment [QOE]. Indeed, some qualitative studies are successful in finding out deeper issues in respect of environmental degradation of urban habitats which should be brought to the notice of urban planners and designers. However, studies carried out in environmental psychology, in many cases, have failed to philosophical underpinnings and appropriateness of methodology. They are unable in theorising the quality of the urban environment to the satisfaction of critical evaluation. The present paper is a humble attempt to critically evaluate the objective and perceptual approaches and methodologies to understand and evaluate quality of the urban environment. In the process, their philosophical foundations are also subjected to critical evaluation to conclude which one of the two approaches better informs policy makers concerned with urban development and renewal programmes.
\end{abstract}

\section{Keywords}

Quality of Urban Environment, Liveability, Objective Approach, Perceptual Approach, Empirical Science, Phenomenology, Hermeneutics

\section{Introduction}

There are several studies available in the developing world, which show concern with the socioeconomic and technological changes taking place in the urban centres. Though, some attention has also been paid to the envi- 
ronmental degradation and quality of environment, laying emphasis on the land use and land cover changes in and around urban centres. These studies largely have shown concern with vanishing green, open spaces, urban agriculture, water bodies, shrinking flood plains and at best micro-climatic changes in the urban environment and not quality of urban environment. Moreover, they generally fail to associate these changes with the liveability of urban habitat or its environmental quality except for impacts on micro-climates or bio-climates which affect human comfort outdoors and indoors in few instances. The theme of quality of urban environment is a relatively recent one in geographical research and there are only a few studies in the context of Indian cities.

The present paper is a humble attempt to critically evaluate so-called objective and perceptual approaches and respective methodologies to understand and evaluate quality of urban environment in order to bring out the fact which one of the two approaches better informs policy makers concerned with urban development and renewal programmes.

It is true that an urban centre is a culturally created artificial system. Pathways of energy flows and material cycles in this system are quite different to those in natural or human managed natural systems. These culturally created systems, because of deviation of pathways of energy and material from natural system, adversely influence the natural environment in and around them. In turn, the natural environment bears on them. Thus, the urban environment as the habitat of humans is a complex system of heterogeneous components, linked together by physical, biotic and social processes (Figure 1).

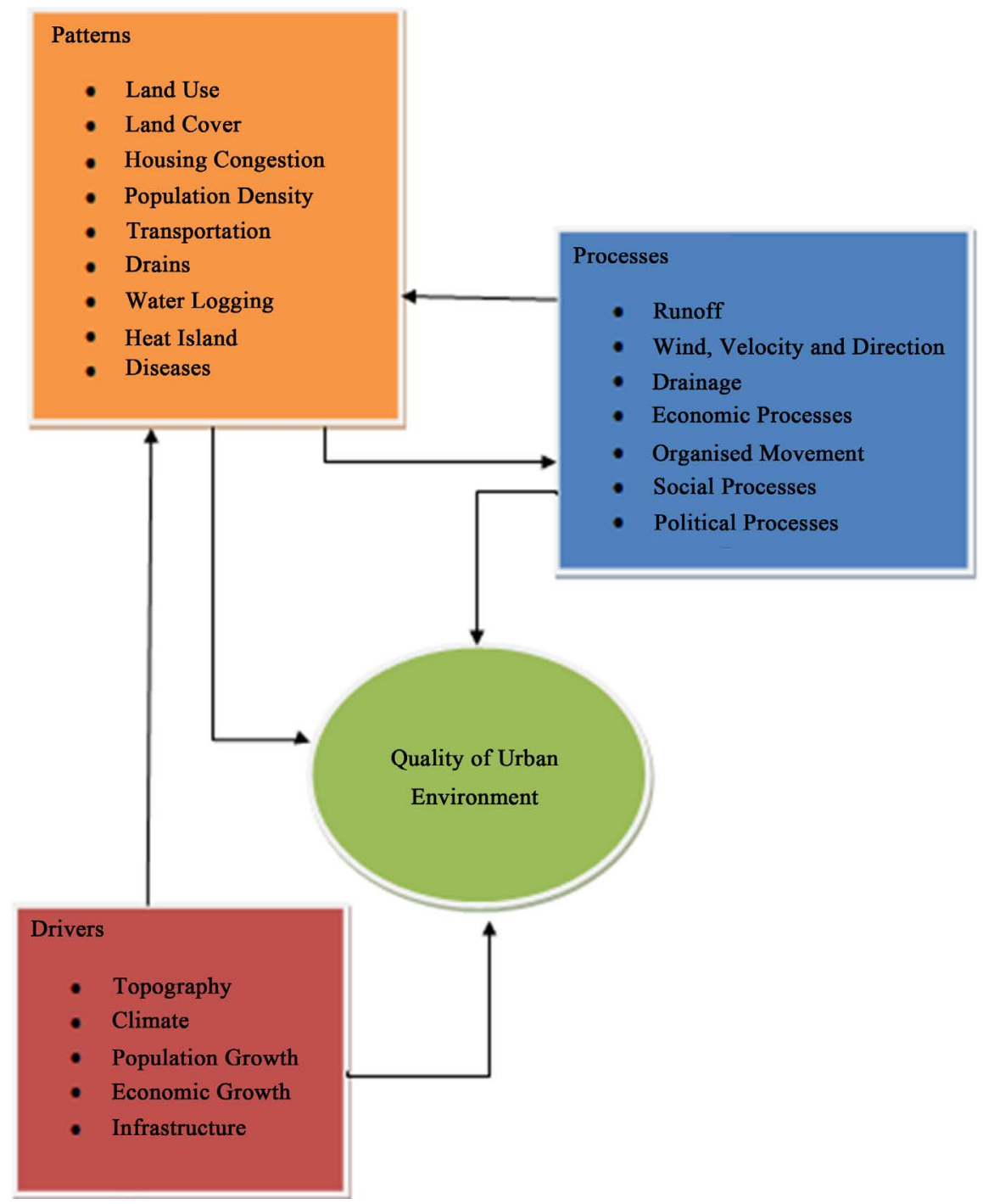

Figure 1. Components of quality of urban environment. 
The qualitative degradation of urban environment resulting in social malaise is the result of spontaneous and uncontrolled production with almost no regard for compatibility with the environment or for the efficient use of energy (Khosla, 1974). The result is development of heat islands, an increase in the water and air pollution, housing congestion, crowding, uncomfortable indoor and outdoor urban environment and even in some instances hot urban street canyons, generating environmental stresses. These stresses make the urban habitat less liveable. The spontaneity and un-manageability of development has also generated trends towards differential accessibility to resources and services. In the developing countries, all this results basically from social pollution because of scarcity, mass poverty and lopsided development. Under the weight of huge population pressure on urban infrastructure, urban authorities have to come to terms with a new wave of in-migrants by reason of recent fast expansion of urban-based industrialisation in the background of the mounting pressure on land in rural areas. The challenges arising from this urban growth exceed capacity of most of the cities to meet even the most basic urban amenities, facilities and services of large proportions of the urban population (UN-HABITAT, 2004).

In the conditions of a socially stratified society and lopsided development, exclusive urban improvement has further accentuated inequalities in environmental quality over urban space, resulting into new areas of qualitatively substandard conditions. However, urban settlements in general are the face of the future in view of the pace of urbanisation in the South.

In this context, a new research tradition has emerged in the western world under the rubric of quality of environment, out of older traditions of quality of life, social indicators, level of living, etc. (Knox, 1974; Niewiaroski, 1965; Fakhruddin, 1991). Despite differences in the research designs of these approaches to the qualitative aspect of human urban habitat, they attempt to connect the habitat with its users. In spite of qualitative difference in the urban crises of the developed and developing countries, the fact remains that the quality of the urban environment has degraded and continues to slide down almost all over the world. Of course, criteria of judgments are different due to the distinctive urbanisation processes, the pace of economic growth and social changes in different parts of the world.

For all their usefulness, the national, regional or local economic criteria are in no way complete measures of the status of the urban environment. In most cases, economic indicators are concomitants of degraded quality of the urban environment. Higher economic level of a place means higher throughput consequent upon generation of large amounts of waste in processes of production, distribution and consumption, if inefficiently managed. This state of affairs ultimately results in all types of environmental pollution and degradation. Since urban settlements in the developing countries are increasingly becoming industrial powerhouses, liveability of these places is deteriorating, often beyond permissible limits.

However, now these economic measures as the indicators of development and qualitative change in the human environmental conditions are being increasingly questioned. Many researchers consider these measures inadequate in accounting fully overall living conditions. It is pointed out that, there exist several ingredients of living conditions and development, as green areas, parks, water bodies, access to healthcare, leisure, clean air, potable water, etc., which are not represented by these gross measures of economic progress. Most importantly, urban settlements due to changes in their ecosystem and townscape are losing their essential attribute of placeness. Further, these measures are also questioned for their inherent positivist approach that has inculcated the belief that increased technological and industrial development automatically leads to a better life. However, as experience of the western countries reveals that, despite generating investment and production, industrialisation is also directly responsible for exacerbation of problems of health, environmental pollution and recreational opportunity. It is, now agreed that, the development and qualitative change in human environmental conditions go beyond some aggregate measures of level of consumption and production of goods and services.

Recently, the problem of assessing the liveability of urban settlements has received much attention in the social indicators approach. The overall composition of housing, health, education, social status, employment, affluence, leisure, social security and social stability exhibited together with associated aspects of demographic structures constitute the levels of living of a community.

However, the expression, quality of environment to describe the state or change in the living conditions, has a subjective connotation. Individual and collective preferences and priorities differ in respective perceptions of good and bad, static and dynamic. The ethnic and cultural diversity and somewhat rigid social stratification in the developing countries indicates that perception of good and bad varies with the beliefs and practices of different ethnic groups and social strata. Thus, subjectivity involved in the approach to QOE complicates the problem of measurement.

Notwithstanding this fact, the studies of quality of environment, with few exceptions, use objective criteria 
which are most readily available. The underlying assumption is that the correlation between objective and perceived (subjective) indicators of QOE is high enough to confirm the results based upon the former. But, there exists meagre empirical evidence to confirm this assumption. Placing emphasis on the importance of perceptual indicators, researchers have argued that the perception of the environment and its objective state are not necessarily equal or have a link (Rojeck, 1975). McCrea et al. (2006: p. 91) in their study of Southeast Queensland have found no "weak link between the objective and subjective latent measures of the urban environment..." Some even believe that there is a real possibility that subjective reports may contradict objective evidence (Easterlin, 1974). Jian and Kazunori (2004) in their attempt at developing a robust method for establishing the assessment system for residential environments could not prove a relationship between subjective and objective models of quality of environment. Since none of the arguments on the relationship between subjective and objective criteria of quality of environment have the support of rigorous empirical research, it is usually suggested that both types of criteria of quality of environment are good enough in evaluating the environmental state of a human habitat (Jian \& Kazunori, 2004).

Here, it should be pointed out that the perceived (subjective) variables of quality of environment are important in the western world, where most of the population enjoys a high standard of living, but in the developing countries perhaps they are not as important. In these countries majority of urban dwellers do not enjoy even the basic amenities, not to speak of highest public amenities. Under such circumstances people do not feel deprived of amenities and facilities because of low levels of expectations and aspirations as compared with others. As such, quality of environment becomes a vague and ethereal concept.

In the context of the emerging economies as India's, where a small population has been barely aware of its conditions and rights in the societal milieu, objective approach to the environmental quality of legally permissible limit is the first preference of a researcher. However, it is to be noted that urban centres, especially big and medium-sized, have become a pacesetter of economic growth, educational development and cultural change. A higher educational level, broader horizon of communication and information have made them aware of their deprivation of rightful environmental quality and raised their aspirations to a higher level. The poor, who seldom realised the systematic process of their deprivation, have become aware of their living conditions in the socio-economic and ecological milieu of the society due to national and regional political churning and because of the work of the NGOs especially awareness created by green movements. They, by now, have become aware of quality of air, water, food and sanitary conditions in and around their houses. In this process they have developed a perception of their urban environmental setting. Therefore, perceptual approach based on personal and community preferences and reactions to the existing environmental quality out of their experience cannot be ignored altogether in emerging economies.

\section{Objective Approach}

Quality itself connotes somewhat subjective evaluation of a person, object or situation. Quality has different meanings to different persons and its evaluation is value-laden. It follows that QOE is a multifaceted reality and an ambiguous concept fraught with divergent views. Being nebulous, it is bound to have different meanings to different people who judge quality of any object, phenomenon or situation out of their lived experience. It also applies to QOE whether of rural or urban habitat.

However, besides in early stages of the research tradition of QOE, empirical research is still considered standard. Perhaps, the foundation of this approach is the Newtonian and Einsteinian traditional epistemology of science. This view presumes the world exists objectively and externally that knowledge is valid only if, based on experience, observation and measurement of this external reality and that universal or general laws exist or that theoretical models developed on these objectives and verifiable facts can explain cause and effect relationships and lend themselves to predictions. This view of reality based upon values of reason, truth and validity focuses purely on facts (objective and verifiable) gathered through direct observations and experiments and measured empirically using instruments or quantitative methods. Hatch and Cunliffe (2006) extend this scientific standpoint to the social reality in the organisational context. They refer to scientific standpoint mentioned above and assume that what truly happens in organisations can only be discovered through categorisation and scientific measurement of the behaviour of people and systems and that language truly represents the reality. Cornerstone of research is formed by axioms or laws (supposedly laws of nature) which are unassailable and theory derives from deductive logic and mathematical manipulation of observations or instrumental or experimental data. The assumption is that the quantitative attempts at generalisation and theory building aid in making informed policy 
decisions about an entity or state by predicting it in future accurately. It needs emphasis that objective reality is too complex to grasp by senses or instrumental rationality with certainty. It is considered wrong in the highest order science of quantum mechanics. Objectivity or distinction between subject and object is no more than a figment of imagination.

Goodman (1978) strongly argues against neutral and verifiable facts. He points out that these are rather social constructs that we have collectively decided as facts. He (1978: 91) emphasises, "These articles of faith, so firmly possess most of us, they so bind and blind us, that 'fabrication of fact' has a paradoxical sound. 'Fabrication' has become a synonym for 'falsehood' or 'fiction' as contrasted with 'truth' or 'fact'. Of course, we must distinguish falsehood and fiction from truth and fact; but we cannot, I am sure, do it on the ground that fiction is fabricated and fact found.”

In fact, reality modelling in any science relies upon our conceptualisation of its structure or arrangement of phenomenon, object or process. We invent and design measuring instruments or recording apparatuses with the purpose to record reality as we think it ought to be. This introduces an element of subjectivity in the observation and description of natural and social entities or processes from quantum to cosmological scales. We have to remember what we see is not nature per se, but nature exposed to our method of questioning or recording and our perception and conceptualisation. In this view not only the states of nature matter, but also states of mind matter.

Furthermore, our scientific work consists in asking questions about nature in the language that we have and trying to get an answer from experiments by the means at our disposal. This language problem in scientific communication has led debate on the criteria for definition of observed and either only intentional or extensional agreement is enough between symbol/word (used to denote the observed) and definiendum. The demand for absolute synonym is grounded in the conviction that the symbol/word must explain unequivocally the meaning of the definiendum. Trouble arises with the notion of meanings and even with the idea of exact sameness. Often there exist multiple alternative symbols/words that are not coextensive are obviously equally admissible. For example, a point in a plane is differently defined either as a certain pair of intersecting lines or as a different pair or as a nest of regions, etc. But the symbol/word having these disjoint extensions surely cannot be coextensive with the definiendum.

Hence, language utterances might not describe reality and can have an effect on reality (Austin, 1962: pp. 1-2). In nutshell "as Bohr has put it, of the old wisdom that when searching for harmony in life one must never forget that in the drama of existence we are ourselves both players and spectators. It is understandable that in our scientific relation to nature our own activity becomes very important when we have to deal with parts of nature into which we can penetrate only by using the most elaborate tools” (Heisenberg, 1958: pp. 24-25). As such, reality is a product of the mind confounded by language and not an object perceived by the senses. Consequently, even our scientific objective reality becomes subjective.

The researchers are not against science or rationality rather appreciate the science of its full worth. But, they do not believe in exclusiveness of the scientific version of reality as only one system, especially that of physics that is all-inclusive or in the possibility of reduction of all versions of reality from various sciences into a theory of everything with some semblance of reason as the only truth about the only one world. In view of the researchers evidence for such reducibility of a complex world is negligible.

Though, the researchers believe in a multi-world version like pluralists, but they do not advocate that science should not treat the world or an object of interest as reality. It must do it, as no other way exists to make one assume that what one observes, is not real, otherwise one could not make use of so-called laws of the nature (in our understanding). However, because one can perceive only information generated by an entity, therefore, one must realise that what one observes is the impulse of reality. The reality of all our observations is only an electromagnetic impulse emitting from stimuli. Human brain receives these signals from our sense organs as impulses from observing the entity or external world and these impulses are the projection of image (percept), sound, taste, smell and touch carried to the brain by a chain of neurons. As Lewis and Pucelik (1982: p. 7) point out "Conscious awareness of our environment is based on a feedback loop comprised of sensory input transmitted to the central nervous system, leading to the construction of our model of the world." Irrespective of the fact whether people consciously perceive the world or not, it should be noted that the impulse of the reality depends on the properties of the entity being perceived and the properties of the perceiver and is also influenced by several other factors, some known and associated and some unconnected. Anyway, reality corresponds to the web of diverse coherent relationships.

In environmental planning of urban habitat, QOE must be defined. It can be done either by a single one or a team of scientists, engineers, architects and others who have to interpret QOE. It sounds no more than a consensual 
approach to meanings of QOE. They may develop a plan for restoring or improving environmental quality on consensual definitions and concepts or have to follow guidelines prepared by the office of concerned governmental agencies. These guidelines to improve quality of the environment are usually the outcome of no more than a consensual theory of environmental quality. Their plans may be scientifically correct, technically feasible and financially viable. But, do these plan aimed at improving quality of environment have a human touch and make people happy and satisfied?

Kurt Friedrich Gödel dealt a devastating blow to empirical science around the first quarter of the 20th century. Gödel's incompleteness theorems say that any system that is complex enough to express in mathematics cannot prove by itself that everything it says is true. It will always rely on something outside the system that one has to assume is true, but cannot prove. In any consistent formal logical system of statements, there will always be a statement that cannot be proved ("a creative intuition" in words of Karl Popper), making the entire system incomplete. Gödel's incompleteness theorems imply that all consistent conceptual systems, including logic and mathematics and, by extension, sciences are incomplete. A single unifying theory is impossible. Reality, in Gödel's formulation, is infinite and any knowledge of it, however, is finite (Meltzer, 1962; Franzén, 2005; Stewart, 1996).

Theories simply are generalisations deduced from sensory impressions of nature and measurements (data) either from field or experiments. Human knowledge consists of a lot of descriptions of facts. Some of those descriptions form a system and are known as models of the reality. But such models do not contain all the descriptions of facts. Therefore, human understanding of the world (knowledge) can be said as the only knowledge of models of the reality. One can legitimately point out, if models of reality involve reduction of the reality (all facts, relevant or irrelevant not accounted for in the model) and incomplete in the sense of Gödel's incompleteness theorems, why do they function when transformed into a piece of technology? In fact, models have enough pertinent facts that make them functional. But, they do not describe reality in totality. In other words, knowledge must remain incomplete and sometimes incorrect when we fail to describe facts correctly by reasons of complexity.

Popper is most critical of mathematical or empirical science. To him (1959: pp. 111-112) "The empirical basis of objective science has ... nothing absolute about it”. He (1959: 24) points out that as a matter of fact, no theory can ever be conclusively falsified. For, on one pretext or other, theory can be kept alive. It is always possible to claim that the experimental results contradicting theory are product of careless experimentation or that the differences which exist between the experimental results and the theory are trivial and will disappear with the advance of our understanding. Popper expressed the same opinion regarding probability (statistical rationality). He (1959: p. 4) writes "Now it is far from obvious, from a logical point of view that we are justified in inferring universal statements from singular ones, no matter how numerous; for any conclusion drawn in this way may always turn out to be false: no matter how many instances of white swans we may have observed, this does not justify the conclusion that all swans are white.” Because, any law-like inductive universal generalisation has a prior probability of zero. And, it follows from the probability calculus that an observation that has a prior probability of zero for any number of occurrences (evidence), the posterior probability of that observation on evidence is zero.

As referred above the reality exists independent of human consciousness as without assuming this one cannot survive and make life better. Therefore, reality may exist in spite of science or observations and so there is validity in recognising realities that are simply claimed to exist or act, whether proven or not. For, to survive, the microcosm of the brain never needs to "truly capture reality." It only needs just enough knowledge to make the next move that allows it to exist for a few more micro-seconds.

Assumptions of traditional science have led to assessment of urban environment in terms of scientific and engineering concept of environment. Land use patterns in towns and cities which have direct bearing on QOE are more dictated by market forces than concerns for environmental quality and hence evaluated in economic terms. An example of such an approach is the conceptual model developed by Shafer et al. (2000) that attempts to integrate the human ecosystem and sustainable community perspective within the context of urban green-way trails. The model recognises the basic relationships between components of a habitat in terms of its physical, social and economic realms, but proposes that "QOL" [or QOE] is the creation of an ongoing interaction between community, environment and economy. The physical environment of the community should exist in such a way that it should support conviviality and offer an environment that creates a liveable place. In this conceptual model "conviviality" and "liveability" are the criteria of QOL [QOE] but does not include the human response to the environment as a measure of liveability. Obviously, this model underlying almost all the empirical studies of QOE of urban habitats leads to a measurement of liveability or conviviality in terms of physical, economic and social attributes of urban 
habitats to develop few or a single measure of QOE of localities.

Problem of conceptualisation of QOE in this way promotes a framework that is used as tool for collection and organisation of measurements obtained from geographical locations. It incorporates multiple ordered constructs which aid in providing a comprehensive evaluation and in clarifying many environmental issues. This also includes a developed structure of environmental dimensions or categories to arrange QOE issues hierarchically. Theoretically, quantitative approach helps cater unique insights into these issues. The insights presented would be either very simple or very complex. For example, scientists in the field can present a set of issues either in a group of environmental dimensions related to urban habitat or geographic locations as the main influences within the habitats. Next step, generally followed is the choice of issues and their generalisation. In this way, chosen issues of existing states of environmental system at certain geographic locations are considered for making informed policy decisions or to take remedial actions to bring back a single or many dimensions of the system to their original or better state for number of habitats. The approach generally employs indicators containing information about states of the environment either theoretically developed or on the basis of observed issues in the field. Sometimes these indicators are also required to gauge the impact of policy decisions on the system of urban settlements or their performance as regard improvement of QOE. The system of environmental indicators derives mostly from a technical and scientific understanding of living conditions of human environment in geographical locations. However, due to limitation of fund and priorities/whims of political class this is not always possible. Trade-offs between science and the policy process resolve issues of standards and benchmarks and which indicators are standards. In this sense, indicators are a product of a compromise between scientific accuracy and the limitations of decision makers, as well as political urgency of action.

Though, certainty in theoretical and empirical sciences do not obtain and observations and measurements do not entail generalisations of reality with which they are compatible, but in appropriate circumstance they serve as the positive evidence for that purpose until other observations falsify it. Husserl's (1969: p. 3; 1999: p. 63) extensive critique of the modern sciences including all positions, e.g. naturalism, empiricism, naïve "objectivism", positivism and related positions entail them a kind of relativism. Taking a relativist stance on the empirical (objective) approach, it dawns on researchers that ad hoc success of empirical models of reality is not without a price, especially in the case of environmental quality. For, translation of the environment into measures of length, mass, weight, volume, velocity and in other similar concepts cannot capture the richness of human experience of a naturally variegated and socially and culturally diverse environment except for some processes. As, a columnist in an Indian newspaper recently has observed that “... in the large cities moon is not visible". The meaning of the moon varies across cultures in accordance with perception by age and sex and aesthetic sense, how can this perception be reduced in numbers? Further, one cannot miss to note that at each step from a choice of indicators to weighing of indicators to add them together into indices to assess reality of QOE, the endeavour is pure simplification of the reality and is not a true representation of the state of the habitat. From the beginning, prescription of indicators represents either scientific or technical concept of QOE or policy makers' limitation of funds or whims of the political class in developing countries. Subjective weighing represents an expert's concept of the importance of indicators, in empirical weighing it is based either on strength of interrelationships of indicators or their some parameters of statistical distribution transformed through some function into weights of indicators. Aggregation of the indicators measured in so many units of measurement involves transformation of indicators such that they become addictive. Irrespective of method of transformation of variables, information loss occurs in the transformation. Naturally, whose concept of QOE is finally represented (certainly not of those who experience it day in day out) or what degree of its objective state gets represented is indeterminate.

\section{Perceptual Approach}

The perceptual point of view of QOE falls in the domain of environmental psychology. Bonnes and Carrus (2004: p. 802) in their contribution to Encyclopaedia of Applied Psychology emphasise, "The starting date of environmental psychology as an autonomous disciplinary field within psychological science is commonly placed at the end of the 1950s." However, Pol (2006) finds the roots of environmental psychology in Geopsyche, the first work of Hellpach (1911), wherein he analyses the effects of climatic and geographical factors on human activities and behaviour at different scales, including urban micro-climates. But, psychologists have explicitly studied the influence of environment on the human behaviour in Anglophone world since the times of Watson (1913). However, before the emergence of environmental psychology as a formal field of research, most environmentally oriented psychologists directed their efforts away from physical environment toward either Lewin's 
(1936) "life space”, the psychological situations as perceived by the person being or micro-environmental "stimuli" of perception and operant psychology in Gibson (1960) and Skinner's (1963) traditions. Though, Barker's (1968) research on behaviour settings, Hall's (1966) and Sommer's (1969) works on territoriality and personal space are important, but Proshansky, Ittelson and Rivlin (1970) and Ittelson, Proshansky, Rivlin and Winkel (1974) articulated foundational and methodological foundation of environmental psychology. Since then, psychologists began to systematically explore the people's transactions with their socio- physical surroundings. In this way, it has emerged from the study of human-environment interactions at various levels of analysis and geographical scales.

Environmental psychology, variously known as environmental, architectural or ecological psychology since its inception has engaged in interdisciplinary discourse with those who design and plan the physical environment, architecture, density, crowding, urban design, etc. This integration of theories and methodologies of different disciplines in environmental psychology during the 1960s and 1970s has prompted much research activity often with collaboration of allied field resulting into rich literature in the areas of crowding, density, personal space, territoriality, environmental perception and cognition and environmental stress during the 1970s (Baum \& Epstein, 1978; Bechtel, 1997; Churchman, 1998; Cohen, 1980; Evans, 1993; Gifford, 1997; Groat \& Despres, 1991; Proshansky, 1971; Stokols, 1978).

Tradition of environmental psychology is the bearer of a venerable tradition in the philosophy of consciousness and psychology that takes sensation as input to perception. Processing of information of perception by cognitive process - a hallmark of higher brain functions - enables mind contemplate the world. It acknowledges the roots of cognition rest in the brain's ability to process information in a time frame that is not governed by immediate changes in the environment. Decision making is a complicated process that is often based on more than one source of evidence. The brain needs to combine these sources to maximise chance of achieving a correct decision. Brain through the cognitive mechanism makes decisions on accumulation of evidence to a subjective criterion level or "threshold". When the collected evidence in favour of one choice reaches this threshold, the brain makes a committed decision, of course, sometimes biased

Environmental cognition is a term that determines how people acquire, store, organise and recall information about the spatial issues, whereas environmental perception is linked to an information processing system in which the individual actively explores the immediate environment. This concept of cognition together with Saarinen's (1976) definition of perception or social perception makes up the theoretical framework in which studies of urban QOE are carried out (Bonaiuto et al., 2003; Brereton et al., 2008; Moro et al., 2008). However, cumulating evidence in neuroscience suggests that socio-cultural contexts generate strong influences on human cognition and underlying neural substrates (Adams et al., 2010; Adolphs, 2009; Boyd \& Richerson, 1985; Butler, Lee, \& Gross, 2007; Chia, 2002; Chiao, 2009; Chiao \& Bebko, 2011; Freeman et al., 2009; Harada, Li, \& Chiao, 2010; Kapogiannis et al., 2009; Olsson \& Ochsner, 2008; Ray et al., 2010; Wu et al., 2010; Xu et al., 2009; Zhu et al., 2007). This has given impetus to an increasing interest in studies of the interaction between socio-cultural factors and multiple levels (e.g., gene, neuron, neural circuit) of the biological basis of human cognitive processes. In neuroscience, it has opened a new field of study, i.e. cultural neuroscience.

Experts have suggested studies of environmental perception and cognition besides the visual qualities of the environment should take into account other qualities of the environment through all senses. Especially, senses of hearing and smell have an important role in organising the environmental and spatial information in the processes of perception and cognition. Sometimes, factors of texture and noise affect the individual behaviour as much as the effects of visual qualities. The perceptual research commonly makes no claim of being completely "objective" and "accurate" of information which goes into the analysis as all senses use transduction of energy or impulse of stimuli into a form that the nervous system can process. Added to it is the advantage of incorporating emotions, feelings, etc. in perceptual approach, which is not possible in the so-called objective approach. This helps find attachment, satisfaction/dissatisfaction with an environment and stresses.

The role of perception and cognition in image formation or assigning meanings to an object, situation or event is important, but no unified theory of image formation exists. In the process of image formation, perception and cognition are tools for simplifying the complex external stimuli. Additionally, the important point that scholars agree that images of two persons about the same objective situation may vary as a result of image processing. This divergent characteristic of images is explained by "the filter process" wherein the perception and cognition play the role of filter in screening the objective information (Golledge \& Stimson, 1997; Warren, 2006). In this model, formation of images about the environment is mentally ordered. Hudson and Pocock (1978) introduce a "filter model" which comprises of the three kinds of responses. As they argue, the first response relates to the 
qualities of "what" and "where", the second one incorporates the evaluation and preferences and the last one is about the predictions and inference consequent upon which the people attach meanings and continuity to the external objects. In this process of filtration, values, beliefs play similar roles. Hence, filters of various types give to an object "meanings" and "image" of an individual which are amenable to psychometric analysis.

This concept of assessment of one's surroundings has, of the necessity, culminated in the tradition of QOE indicators. Instead of social indicators tradition reference here is to the Perceived Residential Environment Quality Indices (PREQIs). Scholars like Bradburn and Caplowitz (1965), Bradburn (1969), Marans and Rodgers (1975), Campbell et al. (1976), Lee and Marans (1980), Cutter (1985), Connerly and Marans (1985, 1988), Rogerson, et al. (1989), Bonnes, et al. (1997), Bonaiuto et al. (1999), Bonaiuto et al. (2003, 2006), Bosque and Martin (2008), Fornara et al. (2010), Bonaiuto et al. (2014), Mao et al. (2015) and others have developed these indices or indicators, enlarged this list for completeness and modified to suit different cultures and environmental situations. Researchers in their assessment of QOE choose variables which they think suit best to the environmental situation under investigation from an exhaustive list. These variables are blended in an interview schedule. This schedule helps to record responses of people. Respondents give only rating to likings and disliking, or approval and disapproval on a five-point and sometimes six-point Likert scale. On this scale respondents are not required to express their opinion in yes or no, but intensity with which an element they perceive as good or bad or intensity with which they prefer an element or do not like in their environment. Do this theoretical approach and method really capture peoples' perception of good and bad? Or, is such type of survey not an opinion poll without freedom to express them otherwise? Architects and urban designers' ways of using images of buildings or streets or plazas or parks etc. to find out peoples' likings and disliking beg similar questions as whether images, pictures, sketches etc. do elicit perception of people about their sense of good and bad. Do peoples' images and meanings which they internally attach to elements of architecture and cityscape are really got represented employing these techniques?

Critical studies have found that socio-spatial and people-environment relations, primarily a field of inquiry dominated by environmental psychologists, are not adequately explained by positivist precepts. The doctrines of positivist science still reign in this area of inquiry within environmental psychology despite many critiques of the similar orthodoxy in the parent discipline, psychology (e.g. Harre \& Secord, 1972; Israel \& Tajfel, 1972; Armistead, 1974; Hudson, 1975). People seldom behave in a way that their behaviour may lead to deterministic predictions which infuse research in environmental psychology. Giddens (1974) has pointed out that studies of people have adopted natural science methodology as the exemplar for research. As such, this interactional approach to human-environment relations treats humans as objects. Further, environmental psychology treats social action and events as being governed by laws which regulate and determine the conduct of human affairs and their behaviour in their surroundings. It assumes that law-like generalisations are possible by accumulation of "facts" and that knowledge of such laws facilitates technical intervention and allows the prediction and control of social behaviour. It is clearly indicated in the remarks of De Young (2013: p. 17), "In an effort to promote durable living on a finite planet, environmental psychology develops, and empirically validates, practical intervention strategies regardless of where the foundational science resides". In so doing, environmental psychology incorporates the work of people who might not otherwise initially be identified with the field (consider for instance, Cone \& Hayes, 1980; Geller, Winett, \& Everett, 1982; Katzev \& Johnson, 1987). Giddens (1974) further notes that the positivist approach treats facts of human affairs as value-neutral. This instrumental concept of facts is in consonance with natural science that allows treatment of information as objective in a technically utilitarian way to resolve conflict of assumption that facts and values are distinct domains.

To conclude, field of mainstream environmental psychology has contributed to perceptual quality of urban environment in terms of social relations, architecture, urban planning and design and urban ecology. However, while there is a great deal in its contributions to subjective QOE that present researchers find encouraging, but the field has been from the beginning Cartesian, positivist, predominantly asocial and additionally naïvely realistic. In spite of misleading explanation and conclusions, there is no denying that some refreshing contributions also have come out of this field. Notable exceptions are Broady $(1966,1975)$ and Daley (1971). However, environmental psychology has remained uninformed by philosophical underpinnings to steer clear of theoretical and methodological pitfalls.

In continental philosophy, phenomenology has got renewed interest in various disciplines for some time. It not only informs psychology albeit environmental psychology, but also neuroscience, leading to a new evolving philosophy generally referred as neuro-philosophy. In its broadest sense, “phenomenology” refers to a person's perception of the meaning of an event, as opposed to the event as it exists externally to the person. The focus of phenomenological inquiry is what people experience phenomena and how they describe those experiences. Hu- 
manistic geography that emerged from behavioural geography about the 1970s has been much informed by phenomenology. As Relph (1977: p. 178) puts it in his commentary on papers of Tuan (1976) and Buttimer (1976) "Phenomenology ... stresses the anthropocentric character of all experience. Any humanistic geography must surely draw on phenomenological concepts and methods". Despite critique of phenomenological contribution to geography, its adherents like E. Relph, Yi-Fu Tuan, Anne Buttimer, David Seamon and several others have made significant contributions to humanistic geography.

Of course, both interactional and phenomenological approaches to environmental psychology consider that "person and environment are mutually defining” (Altman \& Rogoff, 1987: p. 19). Ittelson (1973: p. 18) has already emphasised that people cannot be viewed independently from the situation in which they live, "nor is the environment encountered independent of the encountering individual". In spite of these similarities of the two approaches, Seamon (1982) emphasises important differences between the two approaches with the purpose to highlight philosophical differences between the two approaches, so that an investigator does not remain ambiguous about approach and method.

David Seamon's work has continued the project of Tuan and Relph with advocacy to use phenomenology in the study of human environmental experience because of its descriptive basis and holistic approach to the question of being. He (1982: p. 129) advocates: "For a phenomenological environmental psychology, the term "geographical world" is proper, since it incorporates such qualities as physical space, natural landscape and built environment. A phenomenological environmental psychology examines the experiential aspects of the geographical world. How do environmental elements give and have meaning in people's lives? How do human beings organize their existence spatially? What qualities of landscape and physical environment infuse a physical space with a sense of place?” As Heidegger (1976) states that the world where people exist and the way humans are on the earth, is dwelling and shares Dardel's (1952) view that geography "is the way through which mankind realizes his existence". After all, it is the only sensible world "which the five senses reach toward and interpret" (Seamon, 1982: p. 129).

Use of word, "experience" here is not in ordinary sense of everyday discourse, wherein its sense is self-evident, or in which modern philosophy uses it. It may have been proper in earlier (ancient Greek) philosophy, but it is not sounder for philosophical and scientific discourse in the modern times. Philosophy failed to catch sight of a fundamental region of human experience in terms of its unique structure. Thus, the concept of experience guiding modern philosophy is unacceptable. As mentioned earlier, Husserl shows how scientific crisis has its roots in the alienation which has arisen between the philosophical-scientific interpretation of the world and that understanding of the world that guides us in everyday life. Husserl reproaches modern philosophy for not taking this alienation into consideration. It has "forgotten" the "life world" and, with this, it has forgotten us who live in this world with one another. The forgetting of the "life world" is at the same time a "self-forgetting" (Landgrebe 1973: pp. 1-2). Franz Clemens Brentano, a critic of psychologism of his day-offspring of the empiricism, may have lead Husserl away from empirical science. For, the latter has laid down a pure descriptive science of the psychic life. However, Husserl's way to the problem of experience encompasses the proper way of explaining content of "inner experience" which does not indulge in cause-effect and, therefore, brings into focus the event that has occurred. It is absolute in that no further question behind it is possible. In everyday life people as individuals or as members of a community are usually straightforwardly immersed in various situations of the world, (geographical environment in words of David Seamon) in which they live. Husserl (1970: p. 281) calls this attitude "the natural attitude". Husserl's answer to methodological implications of this natural attitude that investigation should focus on the way we perceive and experience the world and not as it exists "out there" independent of us. Thus, purpose of an investigation is to explore and describe phenomenological, un-reflective and unexamined experience of immersion in the world in the way as it manifests itself to us or precisely as perceived content and meanings ascribed to it in the inner experience.

Thus, phenomenology provides a sound basis for a perceptual assessment of people" s lived experience of QOE as humans experience it (felt environment) and its contents through their five senses; it is just like "lived body". The lived experience of world has root in Martin Heidegger's concept of being-in-the-world. Lived environment or experience of environment is pre-verbal and un-reflective, but humans know that it affects the way they feel. The feelings, emotions and thoughts evoked by it in people's inner experience are assigned meanings. Seamon (1982) provides ontological and epistemological background from existential phenomenology of Martin Heidegger, Jean-Paul Sartre and Maurice Merleau-Ponty on which researchers may decide the method to find out perceived QOE of a place wherein people live.

Husserl believed that subjective information was important to scientists seeking to understand human motivations that are influenced by what people perceive as real. As human beings generally go about the business of 
daily living without critical reflection on their experiences, Husserl believed that an approach was necessary to establish the meaning associated to a particular phenomenon on the basis of life experiences of a specific group of people. Epistemological assumptions of phenomenology encompass the method of investigation and identification of phenomena (Spiegelberg \& Schuhmann, 1994) and discard the philosophy that the world is separate from the person. The first person description of experience is the way to find out how people perceive, whether through analysis of diaries or using oriented interview so that interviewees do not go astray to defeat the purpose of investigation. Investigator uses no questionnaire so that instead of data, people speak for themselves how they perceive their situation and what their lived experience (their reality) is.

An important axiological belief of Husserl's phenomenological method is that it is a must for an investigator inquiring into personal experience to hold back his knowledge, opinions, biases, judgements, etc. in honour of subjective experience of other persons under investigation. As Natanson (1973: p. 727) puts it “...the researcher to shed all prior personal knowledge grasp the essential lived experiences of those being studied." To this end, some experts suggest that a descriptive phenomenologist must not conduct a detailed literature review earlier initiating the study and not to have specific research questions other than the desire to describe the lived experience of the participants in relation to the topic of study (Streubert \& Carpenter, 1999). An important assumption underlying phenomenological investigations is that there are certain features of lived experience which are common to most of the persons who have lived the same environment. These common features of experience referred to as universal essences or eidetic structures that represent true phenomenological experiences and can be derived from descriptions of the participants or respondents. However, they cannot be generalised for whatever purpose because they are true for those who describe them in a particular context. They have utmost importance for planners, designers and architects because people act by what they perceive as true.

Husserl believed that understanding began with experience of phenomena, while Heidegger focused on "dasein", which is generally translated as "the mode of being human" or "the situated meaning of a human in the world". Husserl was interested in acts of intentionality, perceiving and recalling the world and considered humans primarily as knower. Heidegger, in contrast, viewed humans as being primarily concerned creatures with an emphasis on their fate in an alien world (Annells, 1996; Jones, 1975). He also believed (1982) in inseparability of consciousness from the world, but differs in that it is a formation of background lived experience. To him understanding is a basic form of human existence. In this sense, understanding emerges out of people's background (historicality) or situatedness in the world.

However, he doubts that one's background can be made completely explicit. Munhall (1989) described Heidegger as having a view of people and the world as indissolubly related in cultural, social and historical contexts. Consequently, he is critiqued for going too far in the other direction. In fact, hermeneutic phenomenology, as methodology is interpretive. Scholars promoting qualitative investigation believe that it can uncover phenomena for investigation (Plager, 1994). Geanellos (1998: p. 155) succinctly defines hermeneutics as "both the philosophy of understanding and the science of the textual interpretation”. The axiological assumptions of hermeneutics consider the correlation between critical theory and practice. The axiological assumptions of hermeneutics focus on the role of understanding human behaviour in relation to researcher's own behaviour which in a practical way relies upon personal and cultural influences (Annells, 1996). The value associated in the research process encompasses the individualistic perspective of relativism, which stems from individualistic perceptions and experiences and influenced by one's social, cultural, specific, and local aspects of life and experience (Annells, 1996). According to the hermeneutic paradigm, the researcher is able to work freely within the analysis, incorporating their own interpretation on the data collected as a guide to discussion of the results. As a result in attending to description, the principle of "bracketing" so important in Husserl's "transcendental subjectivity" has been relaxed as impracticable.

Implementation of method requires the researchers to consider an insightful approach that is reflective, open-minded and responsive to language (Laverty, 2003). According to Maturana and Varela (1980) and Cole and Avison (2007) the primary goal of the method in hermeneutics is to recognise that research is basically an act of interpretation. Hence, hermeneutics allows investigator" s reflection to make meaning of the experience and analyse thematic aspects of that. Van Manen (1997: p. 32) views this process as "reflectively bringing into nearness that which tends to be obscure that which tends to evade the intelligibility of our natural attitude of everyday life". Generally, this process is complex as meanings, as discussed in the case of objective approach, most often are not straightforward and simple. Meanings are generally multifaceted. An interpretation of the themes (focal points of experience) uncovers the structure of experience.

Hermeneutic researchers may keep a reflective journal to help in the process of understanding underlying 
system of assumptions which may arise during interpretations and research analysis. However, phenomenological "bracket" or set aside bias with the primary goal placed on meanings of texts or description that does not rely on the interpreter (Laverty, 2003). Van Manen (1997) points out that by obtaining descriptions of experience of others, we become more experienced and wiser of an aspect of human experience, in the context of whole.

A flow chart of the objective and perceptual approaches as they deal with the issue of QOE is presented below (Figure 2).

\section{Conclusion}

In the objective approach, the concept of QOE is theory laden, environmental issues and, therefore, their categories are also bound to be theory laden as both are recognised on the basis of a theoretical concept of QOE. Downward the decision what indicators are to be taken into consideration is dictated by issues and, in turn, data are dictated by the operational definition of the indictors as such data are also theory laden. Hence, every aspect is predetermined and, therefore, unreliable. If the concept or theory of QOE is wrong or proved wrong, then whole decision-making and planning will become redundant. On the contrary, in the perceptual approach, first person description leads to meanings and images which usually form eidetic structures or by interpretation the

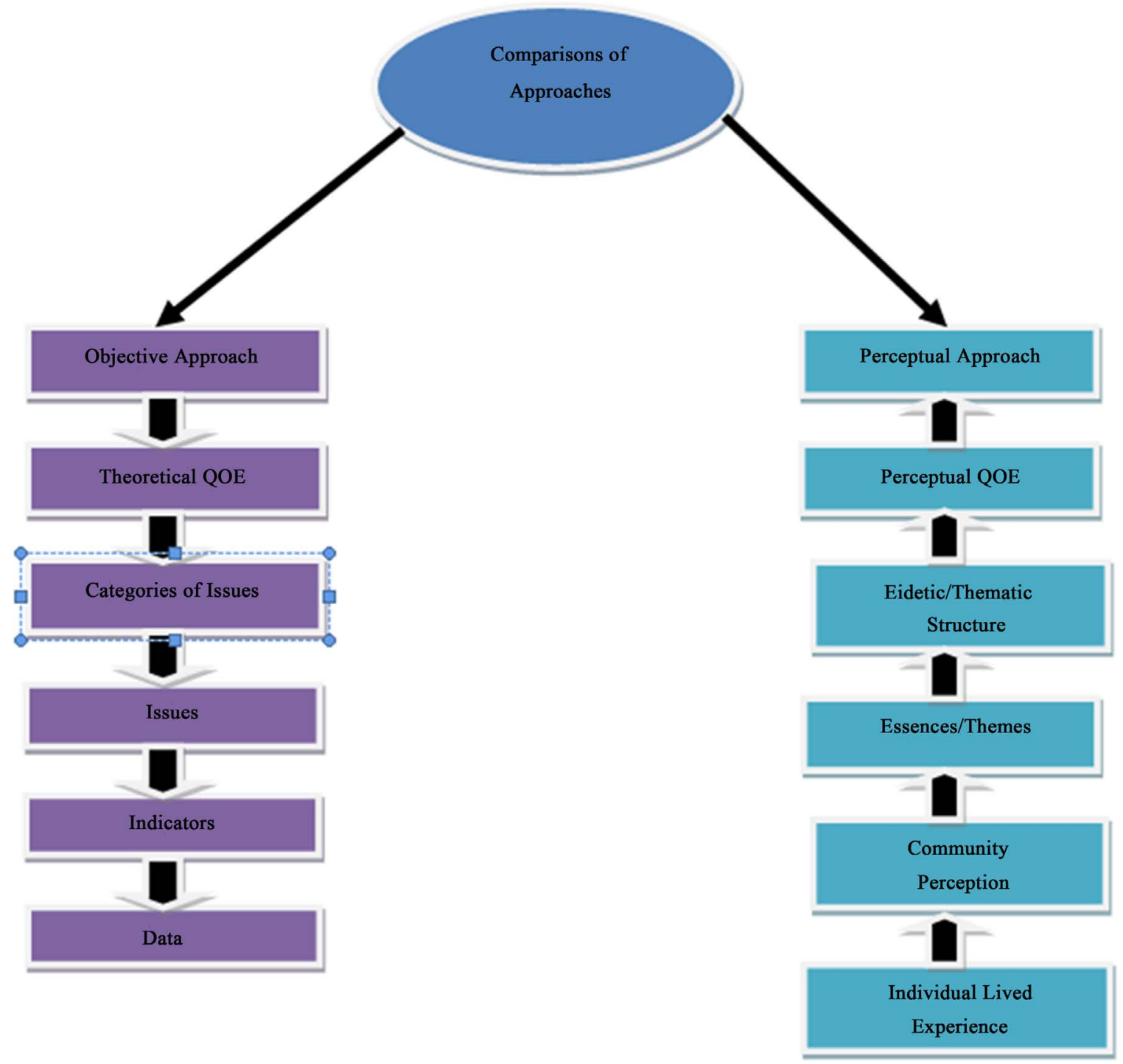

Figure 2. Comparison of objective and perceptual approaches to QOE. 
matic structures of QOE close to the hearts of those who experience it get represented in great measure. Perceptual QOE may be basis of a workable plan of urban design and renewal as people live, work and behave in a framework of values which is closer to reality of existence than the so-called objective reality.

In heterogeneous or plural communities, differences in perception of QOE may be sorted out or resolved through discourse at the local community level via trade-offs. However, it is interesting to note that some perceptual studies have reported that in heterogeneity there is homogeneity of perception with respect to QOE. Azahan et al. (2009: p. 165) report, "All the subgroups of urban dwellers in this study relatively have a homogeneous and average score of the Seremban's (a Malaysian city) quality of life even though they are from a different socio-economic background". It means, uprooted from their own environment, they have totally immersed in the new environment. This approach is generally found helpful in finding out deeper dimensions of QOE. Urban planning and renewal projects based on this approach may prove a motivating force for community participation at all levels including sharing of financial burden as they will take these projects realisation of their dream (image) of a liveable city.

\section{Acknowledgements}

We are highly thankful to scholars on ResearchGate from whose discussions and publications, we are immensely benefited.

\section{References}

Adams, R. B. et al. (2010). Cross-Cultural Reading the Mind in the Eyes: An fMRI Investigation. Journal of Cognitive Neuroscience, 22, 97-108. http://dx.doi.org/10.1162/jocn.2009.21187

Adolphs, R. (2009). The Social Brain: Neural Basis of Social Knowledge. Annual Review of Psychology, 60, 693-716. http://dx.doi.org/10.1146/annurev.psych.60.110707.163514

Altman, I., \& Rogoff, B. (1987). World Views in Psychology: Trait, Interactional, Organismic and Transactional Perspectives. In D. Stokols \& I. Altman (Eds.), Handbook of Environmental Psychology (Volume 1, pp. 245-281). New York: Wiley.

Annells, M. (1996). Hermeneutic Phenemenology: Philosophical Perspectives and Current Use in Nursing Research. Journal of Advanced Nursing, 23, 705-713. http://dx.doi.org/10.1111/j.1365-2648.1996.tb00041.x

Armistead, N. (1974). Experience in Everyday Life. In N. Armistead (Ed.), Reconstructing Social Psychology (pp. 115-132). Baltimore: Penguin Books.

Austin, J. L. (1962). How to Do Things with Words. Oxford: Oxford University Press.

Azahan, A. et al. (2009). The Quality of Life in Malaysia’s Intermediate City: Urban Dwellers Perspective. European Journal of Social Sciences, 9, 161-167.

Barker, R. G. (1968). Ecological Psychology: Concepts and Methods for Studying the Environment of Human Behavior. Stanford, CA: Stanford University Press.

Baum, A., \& Epstein, Y. (Eds.) (1978). Human Response to Crowding. Hillsdale, NJ: Erlbaum.

Bechtel, R. (1997). Environment and Behavior: An Introduction. London: Sage.

Bonaiuto, M., Aiello, A., Perugini, M., Bonnes, M., \& Ercolani, A. P. (1999). Multidimensional Perception of Residential Environment Quality and Neighbourhood Attachment in the Urban Environment. Journal of Environmental Psychology, 19, 331-352. http://dx.doi.org/10.1006/jevp.1999.0138

Bonaiuto, M., Fornara, F., \& Bonnes, M. (2003). Indexes of Perceived Residential Environment Quality and Neighbourhood Attachment in Urban Environments: A Confirmation Study on the City of Rome. Landscape and Urban Planning, 65, 41-52. http://dx.doi.org/10.1016/S0169-2046(02)00236-0

Bonaiuto, M., Fornara, F., \& Bonnes, M. (2006). Perceived Residential Environment Quality in Middle- and Low-Extension Italian Cities. European Review of Applied Psychology, 56, 23-34. http://dx.doi.org/10.1016/j.erap.2005.02.011

Bonaiuto, M., Fornara, F., Ariccio, S., Cancellieri, U. G., \& Rahimi, L. (2014). Perceived Residential Environment Quality Indicators (PREQIs) Relevance for UN-HABITAT City Prosperity Index (CPI). Habitat International, 45, 53-63.

Bonnes, M., \& Carrus, G. (2004). Environmental Psychology, Overview. In C. Spielberger (Ed.), Encyclopaedia of Applied Psychology (pp. 801-814). Amsterdam: Elsevier.

Bonnes, M., Bonaiuto, M., Aiello, A., \& Sensales, G. (1997). Environmental Discourse and Ecological Responsibility in Media Communication in Italy. In R. Garcia-Mira, C. Arce, \& J. M. Sabucedo (Eds.), Responsabilidad ecológica y gestión de los recursos ambientales [Ecological Responsibility and Environmental Resources Management] (pp. 99-135). La Coruna: Diputacion Provincial. 
Bosque, I. R. D., \& Martin, H. S. (2008). Tourism Satisfaction: A Cognitive-Affective Model. Annals of Tourism Research, 35, 551-573. http://dx.doi.org/10.1016/j.annals.2008.02.006

Boyd, R., \& Richerson, P. J. (1985). Culture and the Evolutionary Process. Chicago, IL: University of Chicago Press.

Bradburn, N. M. (1969). The Structure of Psychological Well-Being. Chicago, IL: Aldine.

Bradburn, N. M., \& Caplovitz, D. (1965). Reports on Happiness. A Pilot Study of Behavior Related to Mental Health. Chicago, IL: Aldine Publishing Company.

Brereton, F., Clinch, J. P., \& Ferreira, S. (2008). Happiness, Geography and the Environment. Ecological Economics, 65, 386-396. http://dx.doi.org/10.1016/j.ecolecon.2007.07.008

Broady, M. (1966). Social Theory in Architectural Design. Arena, 81, 149-154.

Broady, M. (1975). Review of Research Application. Architects Journal, 161, 735-739.

Butler, E. A., Lee, T. L., \& Gross, J. J. (2007). Emotion Regulation and Culture: Are the Social Consequences of Emotion Suppression Culture-Specific? Emotion, 7, 30-48. http://dx.doi.org/10.1037/1528-3542.7.1.30

Buttimer, A. (1976). Grasping the Dynamism of Lifeworld. Annals of the Association of American Geographers, 66, 277292. http://dx.doi.org/10.1111/j.1467-8306.1976.tb01090.x

Campbell, A., Converse, P. E., \& Rodgers, W. (1976). The Quality of American Life: Perceptions, Evaluations, and Satisfactions. New York: Russell Sage Foundation.

Chia, R. (2002). The Production of Management Knowledge: Philosophical Underpinnings of Research Design. In D. Partington (Ed.), Essential Skills for Management Research (pp. 1-19). London: SAGE Publications Ltd. http://dx.doi.org/10.4135/9781848605305.n1

Chiao, J. Y. (2009). Cultural Neuroscience: Cultural Influences on Brain Function. Progress in Brain Research. Amsterdam: Elsevier.

Chiao, J. Y., \& Bebko, G. M. (2011). Cultural Neuroscience of Social Cognition. In S. Han, \& E. Pöppel (Eds.), Culture and Neural Frames of Cognition and Communication (On Thinking) (pp. 19-39). Berlin: Springer. http://dx.doi.org/10.1007/978-3-642-15423-2_2

Churchman, A. (1998). A Study of Attitudes towards Housing Issues in the City of Tel Aviv. Haifa: Technion, Center for Urban and Regional Studies.

Cohen, S. (1980). The Aftereffects of Stress on Human Performance and Social Behavior: A Review of Research and Theory. Psychological Bulletin, 88, 82-108. http://dx.doi.org/10.1037/0033-2909.88.1.82

Cole, M., \& Avison, D. (2007). The Potential of Hermeneutics in Information Systems Research. European Journal of Information Systems, 16, 820-833. http://dx.doi.org/10.1057/palgrave.ejis.3000725

Cone, J. D., \& Hayes, S. C. (1980). Environmental Problems: Behavioral Solutions. Monterey, CA: Brooks/Cole Publishing Company.

Connerly, C., \& Marans, R. W. (1985). Comparing Two Global Measures of Perceived Neighbourhood Quality. Social Indicators Research, 17, 29-47. http://dx.doi.org/10.1007/BF00354111

Connerly, C., \& Marans, R. W. (1988). Neighborhood Quality: A Description and Analysis of Indicators. In E. Huttman, \& W. Vleit (Eds.), The US Handbook on Housing and Built Environment (pp. 37-61). Westwood, LA: Greenwood Press.

Cutter, S. L. (1985). Rating Places: A Geographer's View on Quality of Life. Washington DC: Resource Publications in Geography, the Association of American Geographers.

Daley, J. (1971). Technology Models in Architecture-A Critique. In B. Honikman (Ed.), Proceedings of the Architectural Psychology Conference at Kingston Polytechnic, September 1-4, 1970 (pp. 111-115). London: Kingston Polytechnic and RIBA Publications.

Dardel, E. (1952). L'homme et la terre [The Man and the Earth-Geographic Nature of Reality]. Paris: Colin. [Quoted in R. J. Johnston, \& P. Calval (Eds.), Geography since the Second World War: An International Survey. Florence, KY: Routledge].

De Young, R. (2013). Environmental Psychology Overview. In A. H. Huffman \& S. Klein (Eds.), Green Organizations: Driving Change with IO Psychology (pp. 17-33). New York: Routledge.

Easterlin, R. A. (1974). Does Economic Growth Improve the Human Lot? Some Empirical Evidence. In P. A. David, \& M. W. Reder (Eds.), Nations Are Households in Economic Growth (pp. 89-125). New York: Academic Press. http://dx.doi.org/10.1016/b978-0-12-205050-3.50008-7

Evans, F. (1993). Psychology and Nihilism: A Genealogical Critique of the Computational Model of Mind. Albany, NY: SUNY Press.

Fakhruddin (1991). Quality of Urban Life. Jaipur: Rawat Publication.

Fornara, F., Bonaiuto, M., \& Bonnes, M. (2010). Cross-Validation of Abbreviated Perceived Residential Environment Quality (PREQ) and Neighborhood Attachment (NA) Indicators. Environment and Behavior, 42, 171-196.

http://dx.doi.org/10.1177/0013916508330998 
Franzén, T. (2005). Gödel’s Theorem: An Incomplete Guide to Its Use and Abuse. Wellesley, MA: A K Peters, Ltd. http://dx.doi.org/10.1201/b10700

Freeman, J. B., Rule, N. O., Adams Jr., R. B., \& Ambady, N. (2009). Culture Shapes a Mesolimbic Response to Signals of Dominance and Subordination That Associates with Behavior. Neuroimage, 47, 353-359. http://dx.doi.org/10.1016/j.neuroimage.2009.04.038

Geanellos, R. (1998). Hermeneutic Philosophy. Part I: Implications of Its Use as Methodology in Interpretive Nursing Research. Nursing Inquiry, 5, 154-163. http://dx.doi.org/10.1046/j.1440-1800.1998.530154.x

Geller, E. S., Winett, R. A., \& Everett, P. B. (1982). Environmental Preservation: New Strategies for Behavior Change. New York: Pergamon Press.

Gibson, J. J. (1960). The Concept of the Stimulus in Psychology. American Psychologist, 115, 694-703. http://dx.doi.org/10.1037/h0047037

Giddens, A. (Ed.) (1974). Positivism and Sociology. London: Heinemann.

Gifford, R. (1997). Environmental Psychology. Boston, MA: Allyn and Bacon.

Golledge, R. G., \& Stimson, R. J. (1997). Spatial Behavior: A Geographic Perspective. New York: Guilford Press.

Goodman, N. (1978). Ways of Worldmaking. Indianapolis, IN: Hackett.

Groat, L. N., \& Després, C. (1991). The Significance of Architectural Theory for Environmental Design Research. In E. H. Zube, \& G. T. Moore (Eds.), Advances in Environment, Behavior, and Design (Vol. 3, pp. 3-52). New York: Plenum. http://dx.doi.org/10.1007/978-1-4684-5814-5_1

Hall, E. T. (1966). The Hidden Dimension. Garden City, NY: Doubleday \&Co.

Harada, T., Li, Z., \& Chiao, J. Y. (2010). Differential Dorsal and Ventral Medial Prefrontal Representations of the Implicit Self Modulated by Individualism and Collectivism: An fMRI Study. Social Neuroscience, 5, 257-271. http://dx.doi.org/10.1080/17470910903374895

Harre, R., \& Secord, P. F. (1972). The Explanation of Social Behaviour. Oxford: Basil Blackwell.

Hatch, M. J., \& Cunliffe, A. L. (2006). Organization Theory: Modern, Symbolic, and Postmodern Perspectives (2nd ed.). New York: Oxford University Press.

Heidegger, M. (1976). “Basic Principles of Thinking” Translated under the Title “Principles of Thinking”. In J. G. Hart, \& J. C. Maraldo (Eds.), The Piety of Thinking (pp. 46-58). Bloomington, IN: Indiana University Press.

Heidegger, M. (1982). The Basic Problems of Phenomenology. Bloomington, IN: Indiana University Press.

Heisenberg, W. (1958). Physics and Philosophy-The Revolution in Modern Science. London: Penguin Books.

Hellpach, W. (1911). Geopsyche. Leipzig: Engelmann.

Hudson, L. (1975). Human Beings: An Introduction to the Psychology of Human Experience. London: Cape.

Hudson, P., \& Pocock, D. (1978). Focal Problems in Geography: Images of the Urban Environment. London: Macmillan Press Ltd.

Husserl, E. (1969). Formal and Transcendental Logic. The Hague: Nijhoff. http://dx.doi.org/10.1007/978-94-017-4900-8

Husserl, E. (1970). The Crisis of the European Sciences and Transcendental Phenomenology. Evanston, IL: Northwestern University Press.

Husserl, E. (1999). The Essential Husserl: Basic Writings in Transcendental Phenomenology. Bloomington, IN: Indiana University.

Israel, J., \& Tajfel, H. (Eds.) (1972). The Context of Social Psychology: A Critical Assessment. London: Academic Press.

Ittelson, W. (1973). Environment Perception and Contemporary Perceptual Theory. In W. H. Ittelson (Ed.), Environment and Cognition (pp. 141-154). New York: Seminar.

Ittelson, W., Proshansky, H., Rivlin, L., \& Winkel, G. (1974). An Introduction to Environmental Psychology. New York: Holt, Rinehart and Winston.

Jian, G. E., \& Kazunori, H. (2004). Residential Environment Index System and Evaluation Model Established by Subjective and Objective Methods. Journal of Zhejiang University Science, 5, 1028-1034. http://dx.doi.org/10.1631/jzus.2004.1028

Jones, W. T. (1975). The Twentieth Century to Wittgenstein and Sartre. San Francisco, CA: Harcourt Brace Jovanovich.

Kapogiannis, D., Barbey, A. K., Su, M., Zamboni, G., Krueger, F., \& Grafman, J. (2009). Cognitive and Neural Foundations of Religious Belief. Proceedings of the National Academy of Sciences of the United States of America, 106, 4876-4881. http://dx.doi.org/10.1073/pnas.0811717106

Katzev, R., \& Johnson, T. (1987). Promoting Energy Conservation: An Analysis of Behavioural Approaches. Boulder, CO: Westview Press. 
Khosla, A. (1974). Population and Environment. In A. Bose, P. B. Desai, A. Mitra, \& J. N. Sharma (Eds.), Population in India's Development 1947-2000 (pp. 46-47). Delhi: Vikash Publishing House.

Knox, P. L. (1974). Spatial Variations in Level of Living in England and Wales in 1961. Transactions Institute of British Geographers, 62, 1-24. http://dx.doi.org/10.2307/621513

Landgrebe, L. (1973). The Phenomenological Concept of Experience. Philosophy and Phenomenological Research, 34, 1-13. http://dx.doi.org/10.2307/2106776

Laverty, S. M. (2003). Hermeneutic Phenomenology and Phenomenology: A Comparison of Historical and Methodological Considerations. International Journal of Qualitative Methods, 2, 1-29.

Lee, T., \& Marans, R. W. (1980). Subjective and Objective Indicators; Scale Discordance and Interrelationships. Social Indicators Research, 6, 47-64. http://dx.doi.org/10.1007/BF00364601

Lewin, K. (1936). A Dynamic Theory of Personality. New York: McGraw-Hill.

Lewis, B. A., \& Pucelik, F. R. (1982). Magic Demystified: An Introduction to NLP. Lake Oswego, OR: Metamorphous Press.

Mao, Y. H., Fornara, F., Manca, S., Bonnes, M., \& Bonaiuto, M. (2015). Perceived Residential Environment Quality Indicators and Neighborhood Attachment: A Confirmation Study on a Chinese Sample in Chongqing. PsyCh Journal, 4, 123137.

Marans, R. W., \& Rodgers, W. (1975). Toward an Understanding of Community Satisfaction. In: A. Hawley, \& V. Rock (Eds.), Metropolitan America in Contemporary Perspective (pp. 299-352). New York: Halsted Press.

Maturana, H. R., \& Varela, F. J. (1980). Autopoiesis and Cognition: The Realization of the Living. Dordrecht: Reidel. http://dx.doi.org/10.1007/978-94-009-8947-4

McCrea, R., Shyy, T.-K., \& Stimson, R. (2006). What is the Strength of the Link between Objective and Subjective Indicators of Urban Quality of Life? Applied Research in Quality of Life, 1, 79-96. http://dx.doi.org/10.1007/s11482-006-9002-2

Meltzer, B. (1962). On Formally Undecidable Propositions of Principia Mathematica and Related Systems. [Translated from the Original German Work of Kurt Gödel, 1931]. Dover: Basic Books.

Moro, M., Brereton, F., Ferreira, S., \& Clinch, J. P. (2008). Ranking Quality of Life Using Subjective Wellbeing Data. Ecological Economics, 65, 448-460. http://dx.doi.org/10.1016/j.ecolecon.2008.01.003

Munhall, P. (1989). Philosophical Ponderings on Qualitative Research Methods in Nursing. Nursing Science Quarterly, 2 , 20-28. http://dx.doi.org/10.1177/089431848900200109

Natanson, M. (1973). Edmund Husserl: Philosopher of Infinite Tasks. Evanston, IL: North Western University Press.

Niewiaroski, D. H. (1965). The Level of Living of Nations: Meaning and Measurement. Estadistica. Journal of the Inter America Statistical Institute, 64, 3-31.

Olsson, A., \& Ochsner, K. N. (2008). The Role of Social Cognition in Emotion. Trends in Cognitive Sciences, 12 , 65-71. http://dx.doi.org/10.1016/j.tics.2007.11.010

Plager, K. (1994). Hermeneutic Phenomenology: A Methodology for Family Health and Health Promotion Study in Nursing. In P. Benner (Ed.), Interpretive Phenomenology: Embodiment, Caring, and Ethics in Health and Illness (pp. 65-84). Thousand Oaks, CA: Sage. http://dx.doi.org/10.4135/9781452204727.n4

Pol, E. (2006). Blueprints for a History of Environmental Psychology (I). From First Birth to American Transition. Medio Ambiente y Comportamiento Humano [Environment and Human Behaviour], 7, 95-113.

Popper, K. (1959). The Logic of Scientific Discovery. London: Hutchinson \& Co.

Proshansky, H. (1971). The Role of Environmental Psychology for the Design Professions. Paper Presented in Architecture for Human Behaviour: A Mini-Conference and Exhibit, Philadelphia Chapter of American Institute of Architects, 5 April 1971, 75-88.

Proshansky, H., Ittelson, W., \& Rivlin, L. (Eds.) (1970). Environmental Psychology: Man and His Physical Setting. New York: Holt, Rinehart and Winston.

Ray, R. D., Shelton, A. L., Hollon, N. G., Matsumoto, D., Frankel, C. B., Gross, J. J., \& Gabrieli, J. D. E. (2010). Interdependent Self-Construal and Neural Representations of Self and Mother. Social Cognitive Affective Neuroscience, 5, 318323. http://dx.doi.org/10.1093/scan/nsp039

Relph, T. (1977). Humanism, Phenomenology, and Geography. Annals of the Association of American Geographers, 67, 177-183. http://dx.doi.org/10.1111/j.1467-8306.1977.tb01129.x

Rogerson, R., Findlay, A. M., \& Morris, A. S. (1989). Indicators of Quality of Life: Some Methodological Issues. Environment and Planning A, 21, 1655-1666. http://dx.doi.org/10.1068/a211655

Rojeck, D. C., Clement, F., \& Summers, G. F. (1975). Community Satisfaction: A Study of Contentment with Local Services. Rural Sociology, 40, 177-192. 
Saarinen, T. F. (1976). Environmental Planning: Perception and Behaviour. Boston, MA: Houghton Mifflin Company.

Seamon, D. (1982). The Phenomenological Contribution to Environmental Psychology. Journal of Environmental Psychology, 2, 119-140. http://dx.doi.org/10.1016/S0272-4944(82)80044-3

Shafer, C. S., Lee, B. K., \& Turner, S. (2000). A Tale of Three Greenway Trails: User Perceptions Related to Quality of Life. Landscape and Urban Planning, 49, 163-178. http://dx.doi.org/10.1016/S0169-2046(00)00057-8

Skinner, B. F. (1963). Operant Behavior. American Psychologist, 18, 503-515. http://dx.doi.org/10.1037/h0045185

Sommer, R. (1969). Personal Space: The Behavioral Basis of Design. Englewood Cliffs, NJ: Prentice-Hall.

Spiegelberg, H., \& Schuhmann, K. (1994). The Phenomenological Movement. Norwell, MA: Kluwer Academic Publishers.

Stewart, I. (1996). From Here to Infinity. Oxford: Oxford University Press.

Stokols, D. (1978). Environmental Psychology. Annual Review of Psychology, 29, 253-259. http://dx.doi.org/10.1146/annurev.ps.29.020178.001345

Streubert, H., \& Carpenter, D. (1999). Qualitative Research in Nursing: Advancing the Humanistic Perspective (2nd ed.). Philadelphia, PA: Lippincott Williams \& Wilkins.

Tuan, Y.-F. (1976). Humanistic Geography. Annals of the Association of American Geographers, 66, 266-276. http://dx.doi.org/10.1111/j.1467-8306.1976.tb01089.x

UN-Habitat (2004). Youth, Children, and Governance, Global Campaign on Urban Governance. Policy Dialogue Series 2, Nairobi: UN-Habitat.

van Manen, M. (1997). Researching Lived Experience: Human Science for an Action Sensitive Pedagogy. London: Althouse.

Warren, W. H. (2006). The Dynamics of Perception and Action. Psychological Review, 113, 358-389. http://dx.doi.org/10.1037/0033-295X.113.2.358

Watson, J. B. (1913). Psychology as the Behaviorist. Psychological Review, 20, 158-177. http://dx.doi.org/10.1037/h0074428

Wu, Y. H., Wang, C., He, X., Mao, L. H., \& Zhang, L. (2010). Religious Beliefs Influence Neural Substrates of Self-Reflection in Tibetans. Social Cognitive Affective Neuroscience, 5, 324-331. http://dx.doi.org/10.1093/scan/nsq016

Xu, X. J., Zuo, X. Y., Wang, X. Y., \& Han, S. H. (2009). Do You Feel My Pain? Racial Group Membership Modulates Empathic Neural Responses. The Journal of Neuroscience, 29, 8525-8529.

http://dx.doi.org/10.1523/JNEUROSCI.2418-09.2009

Zhu, Y., Zhang, L., Fan, J., \& Han, S. H. (2007). Neural Basis of Cultural Influence on Self Representation. Neuroimage, 34, 1310-1317. http://dx.doi.org/10.1016/j.neuroimage.2006.08.047 